\title{
Identification of 1,3-Dioxolanes in Coffee-Like Flavorings
}

\author{
Fernando Tateo*, Monica Bononi, Elisabetta Lubian, Silvia Martello \\ DIFCA-Sezione di Chimica Analitica Agroalimentare ed Ambientale, Università degli Studi di Milano, Via Celoria 2, 20133 Milano, Italy
}

Ms received: April 7, 1998; accepted: September 25, 1998

Key Words: 1,3-Dioxolanes; acetals; ketals; coffee-like flavorings

\begin{abstract}
Summary
This paper concerns a number of commercially available coffee-like flavoring preparations, identifying certain dioxolane structures of particular interest. The research was carried out by GC/MS, and spectral characterization was performed of the compounds in question, and especially of the acetals and ketals produced from compounds with carbonyl functions and 1,2-propylene glycol. Some determinations by means of chiral gas chromatography and by Isotope Ratio Mass Spectrometry (IRMS) have been useful in improving the analytical characterization of certain dioxolanes.
\end{abstract}

\section{Introduction}

GC/MS studies of the composition of various flavoring preparations and of volatile compounds extracted from flavored food products often indicate the presence of acetals and ketals derived from the reaction of glycols with the carbonyl group of aldehydes and ketones. Many of these compounds, known as 2-RR'4-methyl-1,3-dioxolanes, are of particular interest.

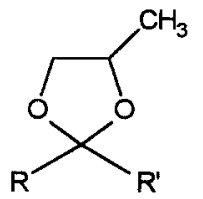

\section{Structure of 2-RR'-4-methyl-1,3-dioxolanes}

So far the authors of this paper have conducted various studies [1-8] on problems relating to the use of 1,2-propylene glycol as a diluent of flavorings and on the spontaneous and/or induced formation of dioxolanes derived from the reaction of 1,2-propylene glycol with various kinds of carbonyl compounds.

GC/MS identification of 2-R, $\mathrm{R}^{\prime}-4-$ methyl-1,3-dioxolanes in flavorings available on the market is one of DIFCA's avenues of applied research, aiming to build up, over time, as complete as possible a pattern of the presence in flavoring preparations of dioxolanes, whether derived from spontaneous reaction due to the presence of the solvent/diluent 1,2-propylene glycol, or because they are used as such and therefore stem from deliberately undertaken synthesis.

The importance of this study lies in the goal of identifying some molecules for possible inclusion in a positive list of artificial flavoring substances. Other authors have established the presence of natural dioxolanes in natural food matrices and/or in flavorings. Among these authors are Mosandl [9] and Bricout [10]. While various 1,3-dioxolanes are indeed found in real life samples, it should be borne in mind that not all of those found in flavorings may be strictly classified as "nature-identical substances". This note presents data for some dioxolane molecules found in research on commercially available coffee-like flavorings.

\section{Materials and Methods}

\subsection{Coffee-Like Flavorings Examined}

The flavorings analyzed include some of those most commonly used in the production of food and beverages on the Italian market and have been designated "C1", "C2", and "C3".

\subsection{HRGC Chiral Analysis}

The analyses were carried out on a Carlo Erba gas chromatograph 5160 MEGA Series (Carlo Erba Strumentazione, Milano, Italy) equipped with a fused-silica capillary column coated with 2,3 -di- $O$-ethyl-6-tert-butyldimethylsilyl- $\beta$-cyclodextrin, $25 \mathrm{~m} \times$ $0.25 \mathrm{~mm}$ i.d., $0.25 \mu \mathrm{m}$ film thickness (MEGA ${ }^{\circledR}$, Legnano, Italy); column temperature, $100^{\circ} \mathrm{C}(10 \mathrm{~min})$, to $220^{\circ} \mathrm{C}$ at $1 \%$ min; injector temperature $200^{\circ} \mathrm{C}$; detector temperature $220^{\circ} \mathrm{C}$; injection mode, split; split ratio 1:20; sample diluted 1:1 in diethyl ether; volume injected $1.0 \mu \mathrm{L}$; carrier gas, $\mathrm{H}_{2}, 40 \mathrm{kPa}$.

\subsection{HRGC/MS Analysis}

The plots, mass data, IRMS values given here were obtained using the following conditions:

a) Shimadzu GC-17A gas chromatograph (Shimadzu Italia s.r.1., Milano, Italy) equipped with a fused-silica capillary column HP 101, $25 \mathrm{~m} \times 0.20 \mathrm{~mm}$ i.d., $0.20 \mu \mathrm{m}$ film thickness (Hewlett-Packard, Cernusco sul Naviglio, Italy) connected directly to a quadrupole mass spectrometer (QP-5000, Shimadzu Italia s.r.l., Milano, Italy); column temperature, $40^{\circ} \mathrm{C}$ $(15 \mathrm{~min})$, to $220^{\circ} \mathrm{C}$ at $1 \% \mathrm{~min}$; injector temperature $220^{\circ} \mathrm{C}$, detector temperature $250^{\circ} \mathrm{C}$; injection mode, splitless (1 min); volume injected $0.2 \mu \mathrm{L}$; carrier gas, $\mathrm{He}, 50 \mathrm{KPa}$.

b) HP 5890 Series II gas chromatograph (Hewlett-Packard, Cernusco sul Naviglio, Italy) equipped with fused-silica capillary column SPB-5, $30 \mathrm{~m} \times 0.20 \mathrm{~mm}$ i.d., $0.20 \mu \mathrm{m}$ film thickness (Supelco, Bellefonte, USA) connected directly to a massselective detector (HP 5971A MSD, Hewlett-Packard, Cernusco sul Naviglio, Italy); column temperature, see (a); injector temperature $220^{\circ} \mathrm{C}$; detector temperature $280^{\circ} \mathrm{C}$; injection mode, split; split ratio $1: 20$; volume injected $0.5 \mu \mathrm{L}$; carrier gas, $\mathrm{He}, 100 \mathrm{KPa}$.

c) Isotope-ratio mass spectrometer "IsoPrime" (Micromass Eurovector s.r.1., Milano, Italy). HRGC conditions were analogous to those stated in (a).

\section{Results and Discussion}

Mass spectra of dioxolanes identified in the coffee-like flavorings analyzed are reported in Figure 1. Table 1 shows the carbonyl compounds from which the corresponding dioxolane structures originate. 


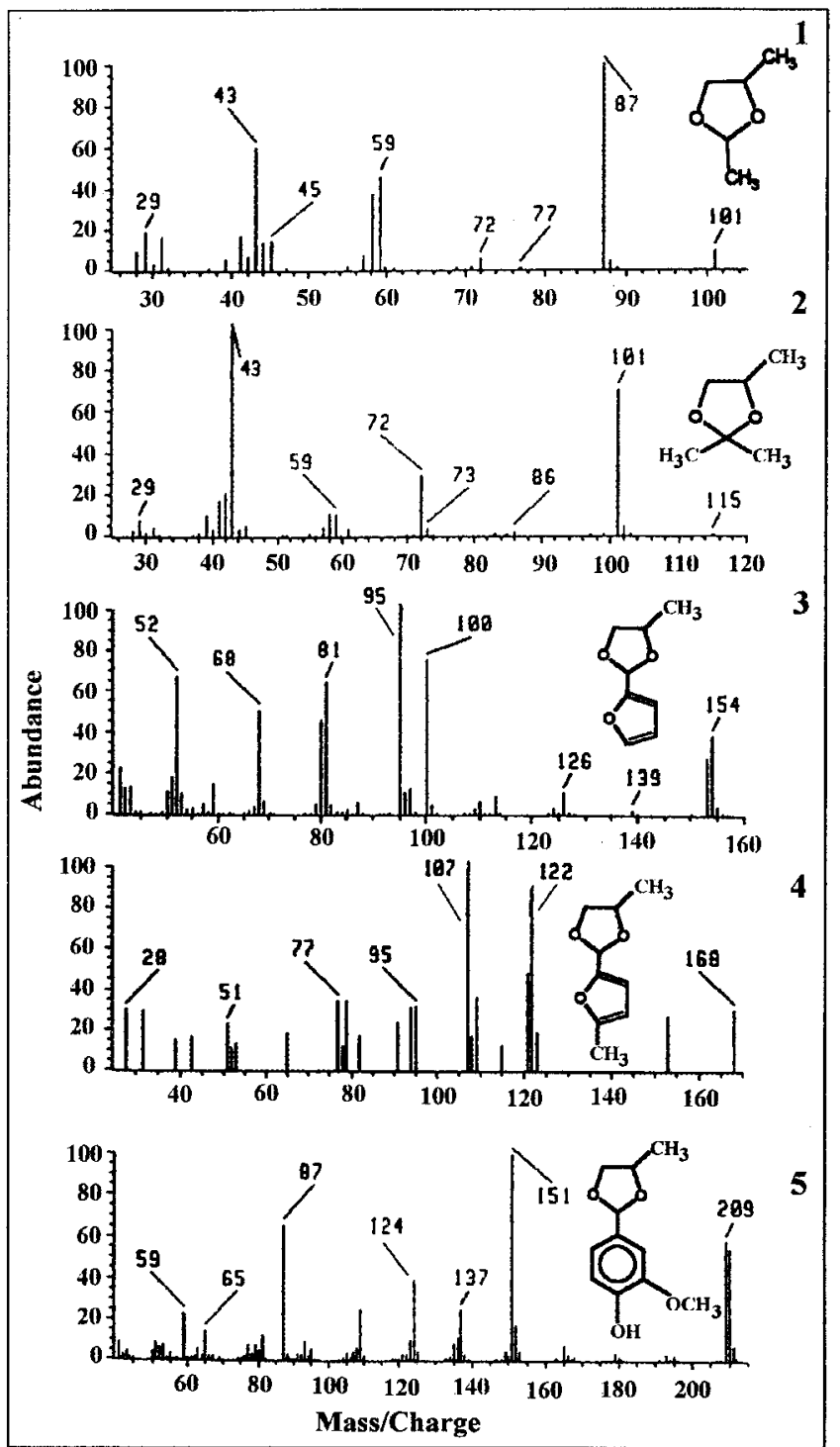

Figure 1. Mass spectra of dioxolanes identified in coffee-like flavorings found on the market. 1) 2,4-dimethyl-1,3-dioxolane; 2) 2,2,4-trimethyl1,3-dioxolane; 3) 2-furyl-4-methyl-1,3-dioxolane; 4) 5-methyl-2-furyl-4methyl-1,3-dioxolane; 5) 2-(3-methoxy-4-hydroxy-phenyl)-4-methyl1,3-dioxolane.

Traces of these compounds are preferably identified by monitoring characteristic ions in the single ion monitoring (SIM) mode. The commonest ion for many dioxolanes derived from 1,2-propylene glycol is $\left[\mathrm{C}_{4} \mathrm{H}_{7} \mathrm{O}_{2}\right]^{+}$, but the abundance of these ions in some structures may be very low, and in some cases negligible.

The presence of the dioxolanes derived from acetaldehyde and vanillin, for example, can be immediately established by monitoring the ion with $\mathrm{m} / \mathrm{z}, 87$ in the SIM mode. The presence of other dioxolanes can be deduced by monitoring different ions (Figure 1). In order to confirm their identity, full mass spectra have to be recorded and the retention times also have to be taken in consideration.

GC and GC/MS analyses with apolar columns give a single peak for each pair of enantiomers and therefore a dioxolane structure with two chiral carbons exhibits two peaks, each peak represent-
Table 1. Carbonyl compounds from which the dioxolane structures of Figure 1 originate.

\begin{tabular}{lll}
\hline Carbonyl compound & $\mathrm{R}$ & $\mathrm{R}^{\prime}$ \\
\hline acetaldehyde & $-\mathrm{H}$ & $-\mathrm{CH}_{3}$ \\
acetone & $-\mathrm{CH}_{3}$ & $-\mathrm{CH}_{3}$ \\
2-furaldehyde & $-\mathrm{H}$ & $-\mathrm{C}_{4} \mathrm{H}_{3} \mathrm{O}$ \\
5-methyl-2-furaldehyde & $-\mathrm{H}$ & $-\mathrm{C}_{5} \mathrm{H}_{5} \mathrm{O}$ \\
3-hydroxy-4-methoxybenzaldehyde & $-\mathrm{H}$ & $-\mathrm{C}_{7} \mathrm{H}_{7} \mathrm{O}_{2}$ \\
\hline
\end{tabular}

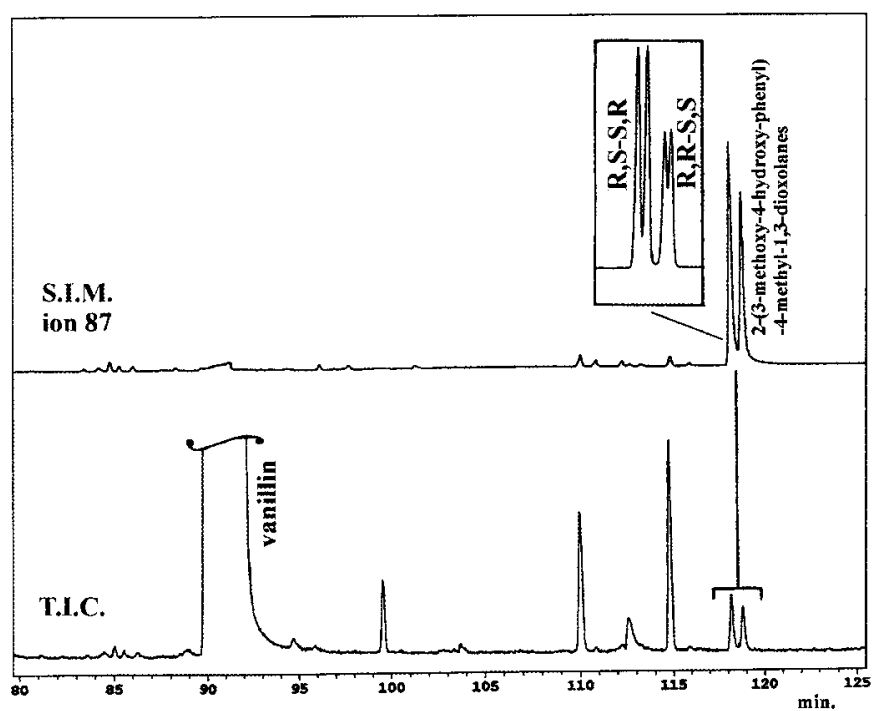

Figure 2. GC/MS identification of dioxolanes derived from vanillin: comparison between the Total Ion and $\operatorname{SIM}(\mathrm{m} / \mathrm{z}$ 87) plots relating to the sample " $\mathrm{Cl}$ ". The insert in the Figure represents the vanillin dioxolanes enantiomeric distribution obtained by chiral column. See Materials and Methods for conditions.

ing a pair of enantiomers. For example, the dioxolanes derived from vanillin found in sample "C1", give two peaks in GC/MS (Figure 2). The chiral column described in "Materials and Methods" separates the two pairs of diastereoisomers, as reported in the insert of Figure 2. Indeed, chiral analysis represents a further criterion for confirming dioxolane identity and the enantiomeric distribution could be a useful indicator of the origin of dioxolanes. To this end, it is useful to compare sample enantiomeric distribution and the corresponding distribution of the dioxolanes obtained by chemical synthesis. Figure 2 shows the typical racemic distribution of the (predominant) cis and trans stereoisomers derived from vanillin. This distribution is characteristic for dioxolanes produced by synthesis using racemic 1,2-propylene glycol.

IRMS analysis obviously gives other information suitable for defining dioxolane origin. The data reported in Table 2 for the sample " $\mathrm{C} 1$ " indicate, for example, that the dioxolane structures are synthetic. A vanillin sample is considered natural if its $\delta^{13} \mathrm{C}$ value is greater than $-21.5 \%$ [11-13].

In sample "C2" it was possible to identify the dioxolanes derived from acetone, 2-furaldehyde and 5-methyl-2-furaldehyde. The 
Table 2. IRMS data from coffee-like flavoring designated "C1". See Materials and Methods for conditions.

\begin{tabular}{|c|c|c|}
\hline Compound & $\begin{array}{l}\text { T.R. } \\
(\mathrm{min})\end{array}$ & $\begin{array}{c}\delta^{13} \mathrm{C} \\
(\% 0 \mathrm{PBD})\end{array}$ \\
\hline Vanillin & 91.4 & -27.03 \\
\hline $\begin{array}{l}\text { 2-(3-methoxy-4-hydroxy-phenyl)-4-methyl- } \\
\text { 1,3-dioxolane (cis) }\end{array}$ & 118.2 & -28.50 \\
\hline $\begin{array}{l}\text { 2-(3-methoxy-4-hydroxy-phenyl)-4-methyl- } \\
\text { 1,3-dioxolane (trans) }\end{array}$ & 118.9 & -28.44 \\
\hline
\end{tabular}

most characteristic ions in this case were those detectable by examining the spectra in Figure 1. Dioxolanes derived from acetone, 2-furaldehyde, and vanillin were also identified in coffeelike flavoring "C3".

Moreover, all three samples of coffee-like flavorings were found to contain 1,2-propylene glycol as a diluent.

\section{Conclusions}

The analytical results relating to coffee-like flavorings highlight the problems associated with the presence of 2-RR'-4-methyl1,3-dioxolanes in food and beverages. Identification of dioxolane structures in aromatized foods and flavorings for which 1,2-propylene glycol is used as a solvent/diluent does not, however, enable us to state that such derivatives are always formed spontaneously.

The compositions of the three coffee-like flavorings do indeed differ, inter alia with regard to the dioxolanes present in the formulations.

It remains difficult to classify these molecules from a regulatory standpoint: a reasonable approach would be to consider "nonnatural", and above all "artificial", those dioxolanes which have not yet been identified as such in natural foods. It would therefore be worthwhile for the Council of Europe to draw up a positive list of flavoring substances and to forbid the use of 1,2-propylene glycol as a diluent in flavorings to be classified as natural or nature-identical.

In fact, EEC Directive n. 88/388 put in practice in Italy as D. L. n. $107\left(25^{\text {th }}\right.$ January 1992) still permits the use of 1,2-propylene glycol as a flavoring diluent.

\section{Acknowledgments}

We thank Micromass Eurovector s.r.1. and Dr. Andy Phillips for their collaboration in IRMS analysis.

\section{References}

[1] F. Tateo, G. Brusotti, Paper presented at the 22nd International Symposium on Essential Oils, Book of Abstracts, St. Vincent, September 11-14, 1991, Società Italiana di Fitochimica.

[2] F. Tateo, G. Brusotti, E. Verderio, in: Riv. Ital. EPPOS, numero speciale Febbraio 92, Actes des 10 èmes Journèes Internationales Huiles Essentielles, Digne-les-Bains, September 5-7, 1991, Istituto Tetrahedron, Milano.

[3] F. Tateo, G. Russo, L. Panza, in: H. Woidich, G. Buchbauer (eds.), Proc. $12^{\text {th }}$ International Congress of Flavours, Fragrances and Essential Oils, Vienna, October 4-8, 1992, Austrian Association of Flavour and Fragrance Industry, Vienna.

[4] F. Tateo, G. Russo, L. Panza, M. Bononi, Riv. Sci. Alim. 1995, 4, 509-512.

[5] A. Ferrillo, Ph. D. Thesis, Università degli Studi di Milano school year 1991/92.

[6] F. Tateo, A. Orlandi, A. Ferrillo, C. Capodanno, L. Panza, G. Russo, Paper presented at the $24^{\text {th }}$ International Symposium on Essential Oils, Book of Abstracts, Berlin, July 21-24, 1993, Technische Universität Berlin, Berlin.

[7] F. Tateo, G. Russo, L. Panza, in: Atti del dell'XI Congresso Nazionale di Chimica Analitica, Chia Laguna, September 12-16, 1994, Società Chimica Italiana.

[8] F. Tateo, M. Bononi, G. Cantele, in: Atti del $2^{\circ}$ Congresso Nazionale di Chimica degli Alimenti, Giardini Naxos, May 24-27, 1995, Società Chimica Italiana.

[9] A. Mosandl, U. Hagenauer-Hener, U. Hener, D. Lehmann, P. Kreis, H.-G. Schmarr, in: Y. Bessière, A.F. Thomas (eds.), Flavour Science and Technology - Proc. $6^{\text {th }}$ Weurman Symposium, Geneva, May, 1990, Wiley, Chichester.

[10] J. Bricout, P. Brunerie, J. Koziet, in: F. Tateo (ed.), News in Flavourings - Proc. $3^{\text {rd }}$ C.N.A. Flavourings International Meeting, Lugano, May 30-31, 1988, Edizioni Cosmondial, Roma.

[11] G. Martin, G. Remaud, in: Riv. Ital. EPPOS, numero speciale Febbraio 92, Actes des 10 èmes Journèes Internationales Huiles Essentielles, Digne-les-Bains, September 5-7, 1991, Istituto Tetrahedron, Milano.

[12] J. Bricout, J.C. Fontes, L. Merlivat, J. Ass. Off. Analytical Chemists. 1974, 57, 713-715

[13] J. Bricout, J. Koziet, M. Derbesy, B. Beccat, Ann. Fals. Exp. Chim. 1981, 74 (803), $691-696$. 